\section{SUPERIOR COMPOSITE TECHNOLOGY}

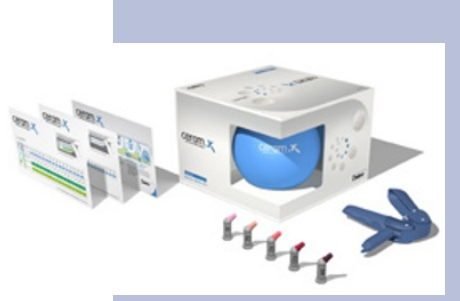

Leaders in developing advanced technologies for superior dental restorative materials, DENTSPLY introduces ceram.X universal. ceram.x universal is a revolutionary nano-ceramic composite material, offering significantly improved physical properties based on SphereTEC, DENTSPLY's new advanced granulated filler technology.

SphereTEC contains almost perfectly round nanoparticles built from sub-micron barium glass particles held together by pre-polymerised resin. This gives ceram.x universal exceptional handling properties:

- Does not stick to hand instruments

- Easy low friction application

- Unmatched adaptation to cavity surfaces

- High stability and slump resistance

- Excellent sculptability enables simple and targeted modelling.

ceram.x universal offers unrivalled shade matching using just five CLOUD A-shades of intermediate translucency, cleverly designed to shade match all 16 VITA classic shades. The unique sub-micron particles within ceram.x universal give superior aesthetics and wear resistance, leading to fast polishing and extra gloss on the finished restoration.

ceram.x universal brings a new dimension to restorative dentistry, combining exceptional handling characteristics and excellent aesthetics to create long lasting restorations.

To find out more contact DENTSPLY on 0800072 3313 or visit dentsply.co.uk.

\section{WELCOME TO SOURCE}

New for 2016, Henry Schein Dental welcomes dental professionals to Source - a single resource which contains everything you need to know about your dental equipment, all in one place.

'Source' is a brand new website that has been developed with the needs of the dental professional in mind and is available to all customers who buy digitally-led equipment from Henry Schein Dental. The site has been launched as a key initiative to support Henry Schein Dental's commitment to providing the very best post-sales support, firmly cementing Henry Schein dental as a leading supplier in the dental equipment market.

The specialist areas include: CEREC, decontamination, digital imaging, laboratory and lasers.

The easy-to-navigate site provides immediate access to all the resources needed to get the most from your surgery equipment.

Visit www.hsdsource.co.uk for further information.

\section{ACT NOW TO AVOID HEFTY PENSION SCHEME CHARGES}

Employers who have delayed setting up their workplace pension scheme may now be subject to hefty initial or monthly charges. Two of the main workplace pension scheme providers have recently imposed a charge to employers.

The People's Pension added a $£ 500$ + VAT set-up charge for employers signing up after 23 November 2015 , reduced to $£ 300+$ VAT if they sign up through a financial adviser.

NOW: Pensions has a monthly service charge ranging from $£ 12.50$ + VAT to £36.00 + VAT depending on the number of employees and whether the employer has a scheme

\section{REDISCOVER YOUR PASSION}

Have you grown tired of micromanaging your dental practice? Have you had enough of signing forms, balancing the books and settling staff disputes?

Do you miss actually practising dentistry?

If so, consider joining Portman Dental. One of the country's most unique dental groups, Portman Dental lends member practices their considerable support and expertise without interfering on a local level. As a result, you will be able to concentrate fully on practising dentistry, while trusting in the team from Portman Dental to

\section{EASING THE STRAIN}

It's no secret that running a successful dental practice, like any small business, takes time, effort and perseverance. Thankfully the team at 7connections has a solution that can help ease the strain.

7 connections, along with Infusionsoft - the US software giant - now offer a solution to enhance your marketing, addressing the entire patient journey from start to finish.

Taking you through each of the seven proven stages from attracting new patients to upselling and increasing referrals, the innovative administered by a payroll bureau using the NOW: Pensions' microsite.

Jon Drysdale, an independent financial adviser from Chartered Financial planners PFM Dental, said: 'Even though your 'staging date' - when you start making contributions to a pension scheme - may be many months away, it makes sense to get your scheme set up as soon as possible to reduce the risk of future set-up or service charges being imposed. It is hard for pension providers to add charges where employers have already signed terms and conditions, so my advice is act now.'

For more information visit www. pfmdental.co.uk.

manage your practice efficiently. With an eclectic expert team, Portman Dental can direct specific expertise into the areas that need it most, ensuring your practice is always the best it can be.

You spent so many years training to be a dentist - return to your passion and let the first-class team from Portman Dental look after the rest. Contact the friendly acquisitions team today to discuss your future.

For more information about joining the Portman Dental team, visit www.portmanhealthcare. co.uk or call Gary Chapman on 02072819489 or 07966698130. 